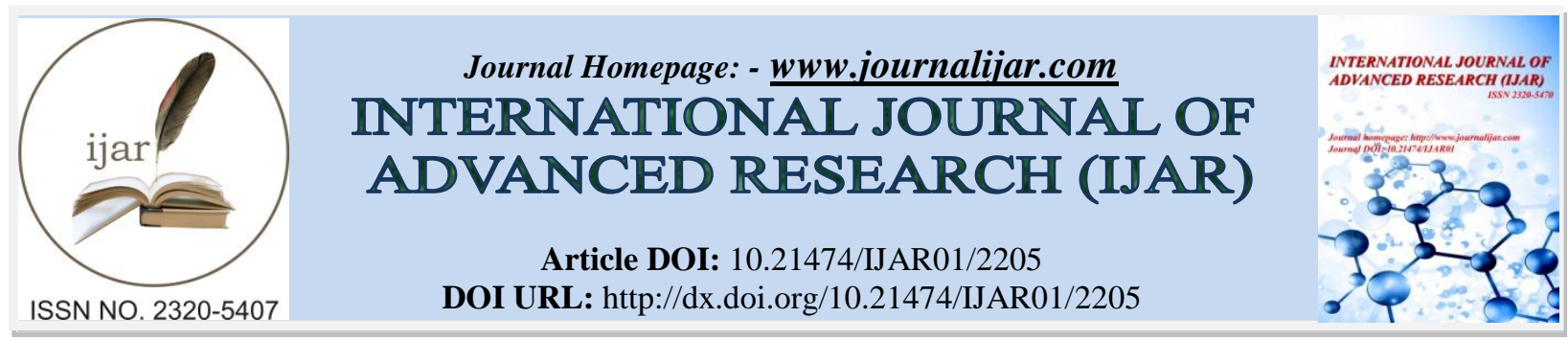

RESEARCH ARTICLE

\title{
EFFECTS OF EMERGENCY OBSTETRICS AND NEONATAL CARE TRAINING ON MATERNAL AND PERINATAL OUTCOMES: KAKAMEGA COUNTY, KENYA.
}

Ameldah Barasa ${ }^{1}$, Charles Mutai ${ }^{2^{*}}$ and Mary Kipmerewo ${ }^{1 .}$

1. School of Nursing and Midwifery, Masinde Muliro University of Science and Technology, Kenya.

2. School of Public Health, Biomedical Sciences \& Technology, Masinde Muliro University of Science and Technology, Kenya.

\section{Manuscript Info}

Manuscript History

Received: 28 September 2016

Final Accepted: 30 October 2016

Published: November 2016

\section{Abstract}

Background: Globally, perinatal mortality rate is 19 deaths per1000 births and maternal mortality is 240 per100, 000 live births. In Africa maternal mortality rate is 500 per100, 000 live births and perinatal mortality is 49 per 1000 births. In Kenya complications related to pregnancy and child birth are the leading causes of maternal mortality translating to 488 per 100,000 live births. In Kakamega District, Maternal mortality rate was 880 per 100,000 live births while perinatal mortality rate was 77 per 1000 pregnancies.

Objective: The main objective of the study was to determine the effect of emergency obstetrics and neonatal care training on maternal and perinatal outcomes in Kakamega County.

Methods: A descriptive cross sectional and retrospective research design was adopted. The target population comprised of frontline healthcare workers trained in EmONC in the 32 health facilities within the county. Purposive sampling technique was used to select 325 respondents. Data was collected using questionnaire, document analysis, observation, and interview and Focus Group discussion. Data was analyzed using descriptive and inferential statistics using Statistical Package for Social Sciences version 21.The finding of this study showed that knowledge and skills of healthcare providers on monitoring a woman in labour improved significantly after the training $(\mathrm{p}<0.05)$. The healthcare providers' knowledge and skills on neonatal care improved as depicted by a Chi-square $(p<0.05)$. Maternal and perinatal mortality rate reduced from 627 in county general hospital, 333 in county hospitals, 458 in sub county hospitals and 80 in health centres in the year 2010 before training to 285 in county general hospital, 48 in county hospitals, 41 in sub county hospitals and there were no maternal deaths in health centres in the year 2015 after the training. However, the healthcare staff experience challenges during EmONC service delivery which include; inadequate staff, inadequate equipments and supplies, inadequate stock of key drugs and consumables and insufficient transport and communication. Conclusion: the County government should address the challenges that interfere with the implementation of EmONC services.

Corresponding Author:- Ameldah Barasa. 
Copy Right, IJAR, 2016,. All rights reserved.

\section{Background:-}

The maternal and child survival are very important in the reproductive health. It is estimated that 289,000 maternal deaths, 2.6 million stillbirths and 2.4 million newborn deaths occur globally each year, with the majority occurring around the time of childbirth (Turab et al., 2013). About 60\% of the estimate death is concentrated in underdeveloped countries. These deaths are attributed to lack of access to skilled birth attendance by pregnant women and inadequate knowledge and skills of healthcare providers in emergency obstetrics and neonatal care (Turab et al., 2013).

Pregnancy and childbirth in resource-poor settings carry significant risk of death and disability. In 1985, the World Health Organization (WHO) announced that approximately 500,000 women die each year from obstetric complications, with upwards of $90 \%$ of these deaths occurring in the developing world (Starrs, 2006). For women in sub-Saharan Africa, where maternal mortality rates are highest in the world, the lifetime risk of dying during pregnancy or childbirth is as high as 1 in 16 (WHO, 2012). In Kenya maternal mortality rate is 488 per 100,000 live births (KDHS ,2008-09).

The medical and surgical interventions to prevent this loss of life are known and most maternal and newborn deaths are in principle preventable (WHO, 2005). There is a need to build the capacity of health-care providers to recognize and manage complications during pregnancy, childbirth and the post-partum period. Skills-and-drills competencybased training in skilled birth attendance, emergency obstetric care and early newborn care (EmONC) is an approach that is successful in improving knowledge and skills (Ameh, 2015).In response to the growing concern over these staggering statistics, the United Nations Population Fund (UNFPA), the World Bank, and the WHO sponsored the Safe Motherhood Conference which galvanized an international campaign to reduce maternal mortality (Starrs, 2006).

In Kakamega District (Kakamega county), Maternal mortality rate is 880 per 100,000 live births while perinatal mortality rate was 77 per 1000 births in 2008 (KDHS, 2008-09). These rates were higher than the national rates of 488 per 100,000 live births. Yet the broad strategies that have made it possible to reduce maternal and perinatal mortality are known: prenatal care, labour and delivery management by qualified personnel, and availability of emergency obstetric care (Campbell et al., 2006). Reduction in maternal and neonatal mortality requires a health workforce with knowledge and skills to manage emergency obstetrics and neonatal events, this was noted in Botswana which had reduced maternal morbidity and mortality, (Campbell et al., 2006).

Giving birth is a natural process, but the transition from a routine to an emergency situation can occur rapidly and unexpectedly. At least $8 \%$ of all labours are associated with an adverse outcome (Nielsen et al., 2007). Enquiries into suboptimal outcomes have identified common errors: confusion in roles and responsibilities, lack of crossmonitoring, failure to prioritize and perform clinical tasks in a structured coordinated manner, poor communication and lack of organizational support (Lewis, 2009). As a consequence, there has been a shift away from individual responsibility towards improved team working. Training of frontline healthcare workers in EmONC will play an important role in maternal newborn health (Lewis, 2009).

Emergency obstetric and newborn care is a package of medical interventions to treat life threatening complications during pregnancy and child birth(Ameh,2012). These services can save the lives of the estimated 280,000 women and 3 million newborns who die annually during pregnancy, child birth and post partum period (Crofts et al.,2007). In Kakamega County, maternal mortality remained high compared to other counties. In order to accelerate the progress of SDG 3, the County Ministry of Health adopted EmONC training as one of the Fast Tract Initiative Roadmap for reducing maternal and newborn death. Following the launch of the training, its effect on maternal and perinatal outcomes has not been studied. The study needed to be carried out to determine the effects of EmONC training on maternal and perinatal outcomes and the results of this study are important for designing and implementing evidence based EmONC programs in the county, scaling up training to all institutions and sustaining regular in-service training. 


\section{Methods:- Study Design:-}

The study used descriptive cross sectional research design. The study also used retrospective design by reviewing the records to find out the maternal and perinatal mortalities before and after the training and knowledge and skills of staffs before the training.

\section{Study Area:-}

The study was carried out in 32 health facilities within Kakamega County. Kakamega County covers a surface area of $3050.3 \mathrm{sq} \mathrm{Km}$ with a projected population of $1,660.651$ million people. The County has both rural and urban population; the majority, 700,300 (83.3\%) being in the rural area. The county has a population density of 515 people per square kilometre and a male to female ratio of 1:5.Maternal neonatal health services are supported by the National government, County government, faith based, and Non-governmental organization. The County is divided into twelve sub-counties for administrative purposes. The county has 128 public health facilities: five county hospitals, seven sub-county hospitals, forty health centres and eighty three dispensaries. The study was carried out in the facilities that offer twenty four hour services for the purpose of getting required sample size. These included: five county hospitals, seven sub-county hospitals, and twenty health centres. The county hospitals have midwives, medical officers, clinical officers, anaesthetists and consultants offering EmONC services. Sub-county hospitals and health centres have midwives, clinical officers and medical officers that offer EmONC services. All the facilities were considered to have equipment and supplies needed for EmONC. The mentioned staffs above were all trained in EmONC.

\section{Study population:-}

The study population comprised of all frontline healthcare workers (midwives, clinical officers, medical officers, anaesthetists paediatricians and obstetricians) trained in emergency obstetric and neonatal care in the 32 health facilities within the county. All the five county hospitals were selected because of high volume of clients. All seven sub-county hospitals were also selected because of the same reason and 20 health centres out of 40 were selected to achieve the required sample for the study. The inclusion criteria was that the health workers must have been trained in Emergency Obstetrics and Neonatal care and are working in maternity and offer 24 hour EmONC services.

\section{Sampling procedure:-}

Purposive sampling was used to get the 5 county hospitals and 7 sub-county hospitals for the study and systematic random sampling was used to select twenty health centres. Kakamega County has got twelve sub counties with 40 health centres distributed among the sub counties. Systematic random sampling was used to select 20 health centres from the 40. A list of health centres in every sub county was created. The first health centre in each sub county was randomly picked followed by every third health centre. The following number of health centres were systematically selected from each sub county:Khwisero-2,Likuyani-2,Mumias East-2,Mumias West-2,Malava-1,Shinyalu2,Navakholo-1,Lugari-2,Butere-2,Matungu-2,Lurambi-1and Ikolmani-1 totalling to 20 health centres. Four county hospitals have 10 frontline healthcare workers working in maternity each and all of them are trained in EmONC totalling to 40. County general hospital Kakamega has 63 frontline health care workers working in maternity but 22 respondents were selected adding up to 62 health care workers from the five county hospitals that participated in the study. Each sub-county hospital had approximately 9 frontline health care workers offering EmONC services totalling to 63.Health centres had 10 healthcare workers in each and all of them rotate in maternity and all of them were selected to participate in the study adding to a total of 200 staffs in 20 selected health centres; all totalling to 325 respondents. Purposive sampling method was used to select respondents in the county, sub-county hospitals and the selected health centres to participate in the study.

\section{Data collection:-}

Data was collected by using various data collection tools in order to answer the research questions. Mixed methods were used to collect both quantitative and qualitative data. Quantitative data was collected using questionnaire, document review interview and observation method while qualitative data was collected through focus group discussion. The questionnaires were administered to the respondents and were requested to fill then return them after answering the questions. The focus group discussion was used to collect data on factors that influence provision of EmONC services. Seven focus group disussions were conducted as follows:one in county general hospital which comprised of 8 participants, one in county hospital which comprised of 6 participants,one in sub county hospital which had 5 participants and four in different selected health centres which comprised of 5 participants in each 
health centre. When conducting a focus group discussion, the moderator developed a moderator guide which outlined the topic and questions to be covered. The moderator introduced herself and covered the agenda of the meeting (general topic) and specific questions to be answered. Allowed the respondents to open up and ensure recording was taking place. Finally noting down any observations and thanked the members.

\section{Data Analysis:-}

All statistical analyses for quantitative data were conducted using SPSS version21. Raw data collected was analyzed by assigning numerical values to each response and entered into a code book or coding table. Thereafter the numerical numbers representing responses from the questionnaires were transferred to a code sheet so as to obtain quantitative results from the closed ended questionnaires. Categorical variables were compared using chisquare tests. Data from interviews and focus group discussion were coded and stored within nodes (descriptive, thematic and analytic). Later these results (both qualitative and quantitative) were summarized, interpreted, and reported.

\section{Ethical considerations;-}

The study was approved by the Ethical Research Committee (ERC) of Masinde Muliro University of Science and Technology and permit granted from National Commission for Science, Technology and Innovation (NACOSTI).

\section{Results:-}

The demographic characteristics of the respondents in this study entailed age, gender, marital status, religion, educational level, and cadre as a health worker. From the study findings, age of the respondents ranged between 25 and 55 years with a mean age of 38 years. Majority of the respondents were aged between 38-48 years as shown by $36.0 \%$ respondents. From the study, most of the respondents, $79.1 \%$ were females. This shows that most of the healthcare providers in the maternity section are females.

In relation to marital status, $44.0 \%$ of the respondents were married followed by $37.5 \%$ who are single. More than a third of the respondents $92.0 \%$ were Christians with the rest $8.0 \%$ being Muslims. The summary of the findings on demographic data of the respondents is as shown in Table 1 below.

Table 1:- Demographic data of the respondents

\begin{tabular}{|c|c|c|c|}
\hline & & Frequency(N) & Percent (\%) \\
\hline \multirow[t]{5}{*}{ Age group } & $20-29$ & 22 & 7.1 \\
\hline & $30-39$ & 130 & 40.9 \\
\hline & $40-49$ & 100 & 31.4 \\
\hline & Above 50 & 68 & 20.6 \\
\hline & Total & 320 & 100 \\
\hline$(\overline{\boldsymbol{X}} \pm$ SD (Range) & \multicolumn{3}{|l|}{$(34 \pm 0.03)(29)$} \\
\hline \multirow[t]{3}{*}{ Gender } & Male & 67 & 20.9 \\
\hline & Female & 253 & 79.1 \\
\hline & Total & 320 & 100 \\
\hline \multirow[t]{6}{*}{ Marital status } & Married & 141 & 44.0 \\
\hline & Single & 120 & 37.5 \\
\hline & Divorced & 2 & .6 \\
\hline & Widowed & 30 & 9.5 \\
\hline & Separated & 27 & 8.3 \\
\hline & Total & 320 & 100 \\
\hline \multirow[t]{4}{*}{ Religion } & Christian & 294 & 92.0 \\
\hline & Muslim & 26 & 8.0 \\
\hline & Hindu & 0 & 0.0 \\
\hline & Total & 320 & 100 \\
\hline
\end{tabular}

\section{R: Range SD: Standard deviation $\bar{X}$ : Mean}

\section{Cadre as a health care worker :-}

The study findings as shown in Table 4.2 shows that, $80.9 \%$ were nursing officers Consultants $0.6 \%, 17.3 \%$ registered clinical officers and $1.2 \%$. The study findings showed that majority of the staff in maternity in the health facilities in Kakamega County were registered nurses. The small number of general doctors in the maternity unit 
$1.2 \%$ hampers the handling of emergency cases. This makes it hard in the development of the strategies to reduce maternal and perinatal deaths.

Table 2:- Cadre as a health care worker

\begin{tabular}{|l|l|l|l|}
\hline Cadre as a health worker & Nursing officer & 259 & 80.9 \\
\cline { 2 - 4 } & Clinical officer & 55 & 17.3 \\
\cline { 2 - 4 } & Medical officer & 4 & 1.2 \\
\cline { 2 - 4 } & Consultant & 2 & 0.6 \\
\cline { 2 - 4 } & Total & $\mathbf{3 2 0}$ & $\mathbf{1 0 0}$ \\
\hline \multirow{4}{*}{ Qualification } & Registered nurse & 259 & 80.9 \\
\cline { 2 - 4 } & Medical officer & 4 & 1.2 \\
\cline { 2 - 4 } & Consultants & 2 & 0.6 \\
\cline { 2 - 4 } & Registered clinical officer & 55 & 17.3 \\
\hline & Total & $\mathbf{3 2 0}$ & $\mathbf{1 0 0}$ \\
\hline
\end{tabular}

\section{Length of time in EmONC interventions:-}

On investigating the length of time the respondents had been involved in EmONC interventions, results shows that majority of the respondents 30.8\% have involved themselves in EmONC for the last two years( Table 3).

Table 3:- Length of time in EmONC interventions.

\begin{tabular}{|l|l|l|l|l|l|l|l|l|}
\hline & \multicolumn{2}{l}{$\begin{array}{l}\text { County } \\
\text { Hospital }\end{array}$} & \multicolumn{2}{l|}{ General } & \multicolumn{2}{l|}{ County Hospitals } & \multicolumn{2}{l|}{$\begin{array}{l}\text { Sub-County } \\
\text { Hospital }\end{array}$} \\
\hline & $\mathrm{N}$ & $\%$ & $\mathrm{~N}$ & $\%$ & $\mathrm{~N}$ & $\%$ & $\mathrm{~N}$ & $\%$ \\
\hline Below one year & 2 & 9.2 & 3 & 7.5 & 3 & 4.8 & 67 & 33.5 \\
\hline One year & 3 & 13.6 & 11 & 27.5 & 10 & 15.9 & 70 & 35.0 \\
\hline Two years & 6 & 27.3 & 14 & 35.0 & 23 & 36.5 & 23 & 11.5 \\
\hline Three years & 7 & 31.8 & 6 & 15.0 & 15 & 23.8 & 14 & 7.0 \\
\hline Above four years & 4 & 18.1 & 3 & 7.5 & 7 & 11.1 & 10 & $5.0 \%$ \\
\hline
\end{tabular}

The analysis of data showed that $27.3 \%$ of the respondents in County General Hospital, $35.0 \%$ from County hospitals, 36.5\% from Sub-County hospital, and $11.5 \%$ from health centres have been implementing EmONC interventions for the past two years

\section{Staffs' knowledge on EmOC services:-}

To assess the knowledge on the provision of EmOC services by healthcare staff the following procedures were considered; monitoring a woman during labour and active management of third stage of labour (Table 4)

Table 4:- Staffs' knowledge on EMOC.

\begin{tabular}{|c|c|c|c|c|c|c|c|c|c|c|c|}
\hline \multirow{3}{*}{$\begin{array}{l}\text { Knowledge of } \\
\text { staff on: }\end{array}$} & \multicolumn{4}{|c|}{ Before training } & \multicolumn{4}{|c|}{ After training } & \multirow[t]{3}{*}{ Df } & \multirow{3}{*}{$\begin{array}{l}\text { Chi- } \\
\text { square } \\
\text { value }\end{array}$} & \multirow[t]{3}{*}{$p$-value } \\
\hline & \multicolumn{2}{|c|}{ Yes } & \multicolumn{2}{|l|}{ No } & \multicolumn{2}{|l|}{ Yes } & \multicolumn{2}{|c|}{ No } & & & \\
\hline & $\mathrm{N}$ & $\%$ & $\mathrm{~N}$ & $\%$ & $\mathrm{~N}$ & $\%$ & $\mathrm{~N}$ & $\%$ & & & \\
\hline \multicolumn{12}{|c|}{ Monitoring a woman in labour } \\
\hline Foetal heart beat & 268 & 83.7 & 52 & 16.3 & 286 & 89.5 & 34 & 10.5 & 319 & 177 & 0.06 \\
\hline Dilation of cervix & 257 & 80.3 & 63 & 19.7 & 292 & 91.4 & 28 & 8.6 & 319 & 123 & 0.05 \\
\hline $\begin{array}{ll}\begin{array}{l}\text { Maternal } \\
\text { pressure }\end{array} & \text { blooc } \\
\end{array}$ & 265 & 82.8 & 55 & 17.2 & 293 & 91.7 & 27 & 8.3 & 319 & 143 & 0.05 \\
\hline Uterine contractions & 226 & 70.5 & 94 & 29.5 & 277 & 86.5 & 43 & 13.5 & 319 & 139 & 0.04 \\
\hline Maternal pulse & 218 & 68.1 & 102 & 31.9 & 292 & 91.4 & 28 & 8.6 & 319 & 132 & 0.04 \\
\hline Maternal temperature & 273 & 85.5 & 47 & 14.5 & 302 & 92.9 & 23 & 7.1 & 319 & 154 & 0.06 \\
\hline Descent of the head & 228 & 71.3 & 92 & 28.7 & 297 & 92.3 & 23 & 7.7 & 319 & 128 & 0.03 \\
\hline $\begin{array}{l}\text { Colour of amniotic } \\
\text { fluid }\end{array}$ & 218 & 68.0 & 102 & 32.0 & 298 & 93.2 & 22 & 6.8 & 319 & 127 & 0.03 \\
\hline Degree of moulding & 223 & 69.8 & 97 & 30.2 & 304 & 95.1 & 16 & 4.9 & 319 & 122 & 0.03 \\
\hline \multicolumn{12}{|c|}{ Active management of third stage of labour } \\
\hline Immediate oxytocin & 224 & 70.8 & 96 & 29.2 & 304 & 95.1 & 16 & 4.9 & 319 & 177 & 0.03 \\
\hline $\begin{array}{l}\text { Controlled } \\
\text { traction }\end{array}$ & 189 & 59.1 & 131 & 40.9 & 303 & 94.8 & 17 & 5.2 & 319 & 123 & 0.03 \\
\hline Uterine massage & 220 & 68.6 & 100 & 31.4 & 310 & 96.9 & 10 & 3.1 & 319 & 143 & 0.03 \\
\hline
\end{tabular}


The study results shows that monitoring a woman in labour improved significantly after the training; assessing dilation of the cervix (from $80.3 \%$ to $91.4 \%$ ), uterine contractions $(70.5 \%$ to $86.5 \%$ ), maternal pulse (from $68.1 \%$ to $91.4 \%$ ), decent of the head (from $71.3 \%$ to $92.3 \%$ ), colour of amniotic fluid (from $68.0 \%$ to $93.2 \%$ ), and degree of moulding (from $69.8 \%$ to $95.1 \%$ ) as shown in Table 4 . on the other hand, monitoring of foetal heart beat (from, $83.7 \%$ to $89.5 \%$ ), maternal blood pressure (from $82.8 \%$ to $91.7 \%$ ), and maternal temperature (from $85.5 \%$ to $92.9 \%$ ). The assessment on active management of third stage of labour improved significantly; that is, immediate administration of oxytocin (from $70.8 \%$ to $95.1 \%$ ), controlled cord traction (from $59.1 \%$ to $94.8 \%$ ), and uterine massage (from $68.6 \%$ to $96.9 \%$ ).

On performing a chi-square analysis, the findings on the healthcare providers' knowledge on EmOC showed that there was a significant relationship between the knowledge of staff before and after the training as depicted by the following, knowledge on: dilation of the cervix $\left(x^{2}=123, d f=319, p=0.05\right)$, uterine contractions $\left(x^{2}=139\right.$, $d f=319$, $\mathrm{p}=0.04)$, maternal pulse $\left(\mathrm{x}^{2}=132, \mathrm{df}=319, \mathrm{p}=0.04\right)$, colour of amniotic fluid $\left(\mathrm{x}^{2}=127, \mathrm{df}=319, \mathrm{p}=0.03\right)$ and degree of moulding $\left(\mathrm{x}^{2}=122, \mathrm{df}=319, \mathrm{p}=0.03\right.$.

\section{Staffs' knowledge on neonatal care:-}

To assess the knowledge on the provision of neonatal care the following procedures were considered; preliminary steps of neonatal resuscitation and care of baby who failed to breathe. The summary of the findings is as shown in Table 4.

In reference to the preliminary steps of neonatal resuscitation, placing of newborn's face up was known by $57.5 \%$ before training and $92.6 \%$ after training. This shows a significant change after the training. Likewise there was an improvement in knowledge on wrapping the baby except for face and upper chest $60.6 \%$ to $95.7 \%$, aspirating the mouth then nose $57.8 \%$ to $91.7 \%$, and stimulating by rubbing the back (from $65.2 \%$ to $92.9 \%$ ).

Table 5:- Staffs' knowledge on neonatal care

\begin{tabular}{|c|c|c|c|c|c|c|c|c|c|c|c|}
\hline \multirow[t]{3}{*}{ Knowledge of staff on: } & \multicolumn{4}{|c|}{ Before training } & \multicolumn{4}{|c|}{ After training } & \multirow[t]{3}{*}{ Df } & \multirow{3}{*}{$\begin{array}{l}\text { Chi- } \\
\text { square } \\
\text { value } \\
\end{array}$} & \multirow{3}{*}{$\begin{array}{l}p \text { - } \\
\text { value }\end{array}$} \\
\hline & \multicolumn{2}{|l|}{ Yes } & \multicolumn{2}{|l|}{ No } & \multicolumn{2}{|l|}{ Yes } & \multicolumn{2}{|l|}{ No } & & & \\
\hline & $\mathrm{N}$ & $\%$ & $\mathrm{~N}$ & $\%$ & $\mathrm{~N}$ & $\%$ & $\mathrm{~N}$ & $\%$ & & & \\
\hline \multicolumn{12}{|c|}{ Preliminary steps of neonatal resuscitation } \\
\hline Place newborn's face up & 184 & 57.5 & 136 & 42.5 & 296 & 92.6 & 24 & 7.4 & 319 & 107 & 0.03 \\
\hline $\begin{array}{l}\text { Wrap baby except for } \\
\text { face and upper chest }\end{array}$ & 194 & 60.6 & 126 & 39.4 & 306 & 95.7 & 14 & 4.7 & 319 & 113 & 0.03 \\
\hline $\begin{array}{l}\text { Position the baby so that } \\
\text { the neck is slightly } \\
\text { extended }\end{array}$ & 186 & 58.2 & 134 & 41.8 & 296 & 92.6 & 24 & 7.4 & 319 & 118 & 0.03 \\
\hline $\begin{array}{l}\text { Aspirate the mouth then } \\
\text { nose }\end{array}$ & 185 & 57.8 & 135 & 42.2 & 293 & 91.7 & 27 & 8.3 & 319 & 113 & 0.03 \\
\hline $\begin{array}{l}\text { Explain the process to } \\
\text { the mother }\end{array}$ & 198 & 61.8 & 122 & 38.2 & 195 & 92.3 & 25 & 7.7 & 319 & 116 & 0.03 \\
\hline $\begin{array}{l}\text { Stimulate by rubbing } \\
\text { back }\end{array}$ & 208 & 65.2 & 112 & 34.8 & 197 & 92.9 & 23 & 7.1 & 319 & 124 & 0.03 \\
\hline \multicolumn{12}{|c|}{ Care of baby who failed to breath } \\
\hline $\begin{array}{l}\text { Continue ventilation } \\
\text { with bag and mask }\end{array}$ & 188 & 58.8 & 132 & 41.2 & 267 & 83.7 & 53 & 16.3 & 319 & 132 & 0.04 \\
\hline $\begin{array}{l}\text { Assess need for special } \\
\text { care }\end{array}$ & 185 & 57.8 & 135 & 42.2 & 282 & 88.3 & 38 & 11.7 & 319 & 126 & 0.04 \\
\hline $\begin{array}{l}\text { Explain to the mother } \\
\text { what is happening }\end{array}$ & 189 & 59.1 & 131 & 40.9 & 286 & 89.5 & 34 & 10.5 & 319 & 128 & 0.04 \\
\hline
\end{tabular}

The knowledge on management of a baby who failed to breath also improved as shown ; continue ventilation with bag and mask ( from $58.8 \%$ to $83.7 \%$ ), assess need for special care (from $57.8 \%$ to $88.3 \%$ ), and explaining to the mother what is happening ( from $59.1 \%$ to $89.5 \%$ ). The results showed a significant association before and after training in terms of knowledge acquired. Knowledge on preliminary steps on neonatal resuscitation improved as follows :place newborn's face up $\left(x^{2}=107, \mathrm{df}=319, \mathrm{p}=0.03\right)$, wrap up baby except for face and upper chest $\left(\mathrm{x}^{2}=113\right.$, 
$\mathrm{df}=319, \mathrm{p}=0.03)$, position the baby so that neck is slightly extended $\left(\mathrm{x}^{2}=113, \mathrm{df}=319, \mathrm{p}=0.03\right)$, aspirate mouth then $\operatorname{nose}\left(x^{2}=113, d f=319, p=0.03\right)$ and stimulate by rubbing the back $\left(x^{2}=124 . d f=319, p=0.03\right)$. Care of the baby who failed to breath improved significantly as follows: continue ventilation with bag and mask $\left(x^{2}=132, d f=319, p=0.04\right)$, assess need for special care $\left(\mathrm{x}^{2}=126, \mathrm{df}=319, \mathrm{p}=0.04\right)$ and explain to the mother what is happening $\left(\mathrm{x}^{2}=128, \mathrm{df}=128\right.$, $\mathrm{p}=0.04)$.

In addition ,during focus group discussion staffs appreciated EmONC training because it improved their knowledge greatly. The following statement was said by one of them "EmONC training improved my knowledge and skills in handling obstetric emergencies and now I am proud of myself for I know what to do during an emergency"(midwife in a county general hospital)

\section{Staffs' skills on EmOC services:-}

The skills on the provision of EmOC services by healthcare staff was assessed through observations of the following procedures: monitoring a woman during labour and active management of third stage of labour. The summary of the findings is as shown in Table 6.

Table 6:- Staffs' skills on EmOC procedures.

\begin{tabular}{|c|c|c|c|c|c|c|c|c|c|c|c|}
\hline \multirow[t]{3}{*}{ Skill of staff on: } & \multicolumn{4}{|c|}{ Before training } & \multicolumn{4}{|c|}{ After training } & \multirow[t]{4}{*}{ Df } & \multirow{4}{*}{$\begin{array}{l}\text { Chi- } \\
\text { square } \\
\text { value }\end{array}$} & \multirow[t]{3}{*}{$p$-value } \\
\hline & \multicolumn{2}{|c|}{ Yes } & \multicolumn{2}{|l|}{ No } & \multicolumn{2}{|c|}{ Yes } & \multicolumn{2}{|l|}{ No } & & & \\
\hline & $\mathrm{N}$ & $\%$ & $\mathrm{~N}$ & $\%$ & $\mathrm{~N}$ & $\%$ & $\mathrm{~N}$ & $\%$ & & & \\
\hline \multicolumn{10}{|c|}{ Monitoring a woman in labour } & & \\
\hline Foetal heart beat & 120 & 37.5 & 200 & 62.5 & 230 & 71.8 & 90 & 28.2 & 319 & 99 & 0.02 \\
\hline Dilation of cervix & 158 & 49.5 & 162 & 50.5 & 233 & 72.9 & 87 & 27.1 & 319 & 106 & 0.03 \\
\hline $\begin{array}{l}\text { Maternal blood } \\
\text { pressure }\end{array}$ & 124 & 38.8 & 196 & 61.2 & 230 & 72.0 & 90 & 28.0 & 319 & 94 & 0.02 \\
\hline $\begin{array}{l}\text { Uterine } \\
\text { contractions }\end{array}$ & 126 & 39.4 & 194 & 60.6 & 218 & 68.0 & 102 & 32.0 & 319 & 114 & 0.03 \\
\hline Maternal pulse & 119 & 37.3 & 201 & 62.7 & 233 & 72.9 & 87 & 27.1 & 319 & 118 & 0.03 \\
\hline $\begin{array}{l}\text { Maternal } \\
\text { temperature }\end{array}$ & 137 & 42.8 & 183 & 57.2 & 234 & 73.2 & 86 & 26.8 & 319 & 114 & 0.03 \\
\hline $\begin{array}{l}\text { Descent of the } \\
\text { head }\end{array}$ & 129 & 40.3 & 191 & 59.7 & 236 & 73.8 & 84 & 26.2 & 319 & 113 & 0.03 \\
\hline $\begin{array}{ll}\text { Colour } & \text { of } \\
\text { amniotic fluid }\end{array}$ & 119 & 37.3 & 101 & 62.7 & 223 & 69.8 & 97 & 30.2 & 319 & 106 & 0.02 \\
\hline $\begin{array}{ll}\text { Degree } & \text { of } \\
\text { moulding } & \end{array}$ & 125 & 39.1 & 195 & 60.1 & 218 & 68.0 & 102 & 32.0 & 319 & 99 & 0.02 \\
\hline \multicolumn{12}{|c|}{ Active management of third stage of labour } \\
\hline $\begin{array}{l}\text { Immediate } \\
\text { oxytocin }\end{array}$ & 227 & 70.8 & 93 & 29.2 & 304 & 95.1 & 16 & 4.9 & 319 & 99 & 0.02 \\
\hline $\begin{array}{l}\text { Controlled cord } \\
\text { traction }\end{array}$ & 189 & 59.1 & 131 & 40.9 & 303 & 94.8 & 17 & 5.2 & 319 & 106 & 0.03 \\
\hline Uterine massage & 220 & 68.6 & 100 & 31.4 & 310 & 96.9 & 10 & 3.1 & 319 & 94 & 0.03 \\
\hline
\end{tabular}

The study results shows that skills on EmOC procedures on monitoring a woman in labour improved significantly after the training; foetal heart beat (from $37.5 \%$ to $71.8 \%$ ), dilation of the cervix (from $49.5 \%$ to $50.5 \%$ ), uterine contractions (39.4\% to $60.6 \%$ ), maternal pulse (from $37.3 \%$ to $72.9 \%$ ), decent of the head (from $40.3 \%$ to $73.2 \%$ ), colour of amniotic fluid (from $37.3 \%$ to $69.8 \%$ ), and degree of moulding (from $39.1 \%$ to $68.0 \%$ ) as shown in Table 6.

The skills on active management of third stage of labour improved significantly $(p<0.05)$, oxytocin was immediately used, controlled cord traction and uterus massage were correctly applied after the training. The test statistic in Table 6 shows that there is significant $(\mathrm{p}<0.05)$ change in the practice before the training and after the training. The findings on the skills on EmOC by the healthcare providers showed that there is difference between the observed practices before and after the training as depicted by the following values: skills on monitoring a woman in labour which includes foetal heart beat $\left(x^{2}=99, \quad d f=319, \quad p=0.03\right)$, uterine contractions $\left(x^{2}=114\right.$, 
$\mathrm{df}=319 . \mathrm{p}=0.03)$, descent of the head $\left(\mathrm{x}^{2}=113, \mathrm{df}=319, \mathrm{p}=0.03\right)$. Active management of third stage of labour improved as follows: immediate oxytocin $\left(\mathrm{x}^{2}=99, \mathrm{df}=319, \mathrm{p}=0.02\right)$ and controlled cord traction $\left(\mathrm{x}^{2}=106, \mathrm{df}=319, \mathrm{p}=0.03\right)$.

\section{Staffs 'skills on neonatal care provision:-}

The skills of staffs on neonatal care was assessed by observation of the following procedures: Preliminary steps of neonatal resuscitation and care of the baby who failed to breath and the results summarized in table 7 below;

Table 7:- Staffs' skills on neonatal care procedures.

\begin{tabular}{|c|c|c|c|c|c|c|c|c|c|c|c|}
\hline \multirow[t]{3}{*}{ Skill of staff on: } & \multicolumn{4}{|c|}{ Before training } & \multicolumn{4}{|c|}{ After training } & \multirow[t]{3}{*}{ Df } & \multirow{3}{*}{$\begin{array}{l}\text { Chi- } \\
\text { square } \\
\text { value }\end{array}$} & \multirow{3}{*}{$\begin{array}{l}p \text { - } \\
\text { value }\end{array}$} \\
\hline & \multicolumn{2}{|l|}{ Yes } & \multicolumn{2}{|l|}{ No } & \multicolumn{2}{|l|}{ Yes } & \multicolumn{2}{|l|}{ No } & & & \\
\hline & $\mathrm{N}$ & $\%$ & $\mathrm{~N}$ & $\%$ & $\mathrm{~N}$ & $\%$ & $\mathrm{~N}$ & $\%$ & & & \\
\hline \multicolumn{12}{|l|}{$\begin{array}{l}\text { Preliminary steps } \\
\text { neonatal resuscitation }\end{array}$} \\
\hline Place newborn's face up & 155 & 48.3 & 165 & 51.7 & 198 & 61.8 & 122 & 31.2 & 319 & 106 & 0.03 \\
\hline $\begin{array}{l}\text { Wrap baby except for face } \\
\text { and upper chest }\end{array}$ & 164 & 51.4 & 156 & 48.6 & 293 & 91.7 & 27 & 8.3 & 319 & 118 & 0.03 \\
\hline $\begin{array}{l}\text { Position the baby so that the } \\
\text { neck is slightly extended }\end{array}$ & 137 & 42.8 & 183 & 57.2 & 243 & 76.0 & 77 & 24.0 & 319 & 122 & 0.03 \\
\hline $\begin{array}{l}\text { Aspirate the mouth then } \\
\text { nose }\end{array}$ & 146 & 45.5 & 174 & 54.5 & 258 & 80.6 & 62 & 19.4 & 319 & 120 & 0.03 \\
\hline $\begin{array}{l}\text { Explain the process to the } \\
\text { mother }\end{array}$ & 137 & 42.8 & 183 & 57.2 & 238 & 74.5 & 82 & 25.5 & 319 & 118 & 0.03 \\
\hline Stimulate by rubbing back & 152 & 47.4 & 168 & 52.6 & 252 & 78.8 & 68 & 21.2 & 319 & 120 & 0.03 \\
\hline \multicolumn{12}{|c|}{ Care of baby who failed to breath } \\
\hline $\begin{array}{l}\text { Continue ventilation with } \\
\text { bag and mask }\end{array}$ & 129 & 40.3 & 191 & 59.7 & 219 & 68.3 & 101 & 31.7 & 319 & 126 & 0.04 \\
\hline Assess need for special care & 137 & 42.7 & 183 & 57.3 & 233 & 72.9 & 87 & 27.1 & 319 & 132 & 0.04 \\
\hline $\begin{array}{l}\text { Explain to the mother what } \\
\text { is happening }\end{array}$ & 189 & 59.1 & 131 & 40.9 & 227 & 71.1 & 93 & 28.9 & 319 & 138 & 0.04 \\
\hline
\end{tabular}

The skills on preliminary steps of neonatal resuscitation which was low before the training improved significantly after the training as depicted by; place newborn's face up ( from $48.3 \%$ to $61.8 \%$ ), wrap baby except for face and upper chest (from 51.4\% to 91.7\%), position the baby so that the neck is slightly extended (from $42.8 \%$ and $76.0 \%$ ), aspirate the mouth then nose (from $45.5 \%$ to $80.6 \%$ ), and stimulate by rubbing the back (from $47.4 \%$ to $78.8 \%$ ). The summary of the findings is as shown in Table 7.

Additionally, there is significant difference between the skills acquired before and after the training in reference to the care of the baby who failed to breath; continued ventilation with bag and mask (from $40.3 \%$ to $68.3 \%$ ), assess need for special care (from $42.7 \%$ to $72.9 \%$ ) and explaining to the mother what is happening ( from $59.1 \%$ to $71.1 \%$ ). On performing a chi-square analysis to test the significance of the difference between the response before and after the training, study findings showed that summary of the $p$-values are all less than 0.05 hence the difference is statistically significant.

\section{Factors that influence provision of emergency obstetrics and neonatal care:-}

Despite the staffs having knowledge and skills on EmONC there were factors that influenced their performance and they were highlighted during the focus group discussions and also through facility assessment .One focus group discussion was done in county general hospital , one in one of the county hospitals ,two in the sub county hospitals and four in the health centres that participated in the study .A number of factors were highlighted as follows: distance of the facility from the referral facility, inadequate trained personnel 24 hours daily, availability of key drugs and poor infrastructure.

\section{Distance of the health facility from the referral facility:-}

It was found out from the focus group discussions that most of the facilities were far from the referral facility (over $20 \mathrm{~km}$ ). The health centres and sub county hospitals refer their emergencies to the county hospitals and the county general hospital which are far. Kakamega County is large and the most equipped facility to handle obstetric and 
neonatal emergencies is the County Referral Hospital. The distance between the County Referral Hospital, which is well equipped, is over $20 \mathrm{Km}$ from some rural health facilities and this results in delays in delivering EmONC services. Delays in reaching an appropriate obstetric facility once the decision to seek care has been made constitute a delay in seeking EmONC services. A majority of the patients from the rural health facilities first sought care in a dispensary or health centre, from where they were referred to the County Hospital or County referral hospital. This often meant that women had to organise their own public transport because the available ambulance were inadequate as they were few with Poor road infrastructure .The following is a narrative from one of the midwives"

"In one of the nights while on duty, a patient was brought to the facility at around 8pm. I was alone on duty. The baby's head could be seen but the patient had no enough power to push. I called for the ambulance and was informed that it had gone to pick a patient at a nearby health facility. This resulted in a delay in the referral of the patient. It was a painful experience as the patient did not have enough money to seek for a private mode of transport". (Midwife health centre).

Availability of staff 24 hours daily:-

It was highlighted that most of the health facilities did not have adequate staff to offer EmONC services. When few EmONC staff attend to a large number of women needing EmONC services, their capacity to give maximum attention to clients is hampered due to provider burnouts, leading to low quality care as seen in the interviews excerpt below.

"Work is sometimes a lot due to high number of clients. Care providers are few leading to burnouts. It is even worse when some providers are absent or attending to other issues or on leave. You will have to attend to clients in other units such as child immunization, family planning, or dispensing drugs in addition to the ANC. Clients will have to wait longer to be served and you will not be able to give them quality time”.(in charge health centre ).

This explains the missed opportunities seen in the provision of health education on complication readiness and birth preparedness as components of antenatal care. When staffs were interviewed about the causes of substandard care, the following was said;

"Sometimes the problem is that the staffs needed are not available; they are not staying in the hospital, the doctor on call stays home. The nurse who can give blood is not available. People are not available ... One day we suggested the laboratory technician and the doctor to stay in the hospital. But they refused. If they stay until morning, they will want to go home to rest but they are needed at hospital every day" (Nurse)

Availability of key drugs and consumables:-

The availability of drugs in the health facilities and specifically the maternity unit ensures efficient delivery of EmONC services. In this study a summary of the availability of the drugs in the facilities is shown in table 8 .

Table 8:- Availability of key drugs

\begin{tabular}{|l|l|l|l|l|l|l|l|}
\hline & & \multicolumn{2}{l|}{$\begin{array}{l}\text { Not } \\
\text { available }\end{array}$} & \multicolumn{2}{l|}{$\begin{array}{l}\text { Available but not } \\
\text { adequate }\end{array}$} & $\begin{array}{l}\text { Available } \\
\text { adequate }\end{array}$ \\
\hline Infrastructure & Facility & N & $\%$ & N & $\%$ & N & $\%$ \\
\hline Antibiotics & County General hospital & 0 & 0.0 & 0 & 0.0 & 1 & 100.0 \\
\hline & County hospital & 0 & 0.0 & 1 & 25.0 & 3 & 75.0 \\
\hline & Sub-County Hospital & 0 & 0.0 & 2 & 28.6 & 5 & 71.4 \\
\hline & Health centres & 3 & 15.0 & 12 & 60.0 & 5 & 25.0 \\
\hline Anticonvulsants & County General hospital & 0 & 0.0 & 0 & 0.0 & 1 & 100.0 \\
\hline & County hospital & 0 & 0.0 & 2 & 50.0 & 2 & 50.0 \\
\hline & Sub-County Hospital & 0 & 0.0 & 6 & 86.0 & 1 & 14.0 \\
\hline & Health centres & 4 & 20.0 & 12 & 60.0 & 4 & 20.0 \\
\hline Hydralazine(oral) & County General hospital & 0 & 0.0 & 0 & 0.0 & 1 & 100.0 \\
\hline & County hospital & 0 & 0.0 & 0 & 0.0 & 4 & 100.0 \\
\hline & Sub-County Hospital & 0 & 0.0 & 2 & 71.4 & 5 & 28.6 \\
\hline & Health centres & 6 & 30.0 & 12 & 60.0 & 2 & 10.0 \\
\hline Anti-malarial & County General hospital & 0 & 0.0 & 0 & 0.0 & 1 & 100.0 \\
\hline & County hospital & 0 & 0.0 & 0 & 0.0 & 4 & 100.0 \\
\hline & Sub-County Hospital & 0 & 0.0 & 2 & 28.6 & 5 & 71.4 \\
\hline
\end{tabular}




\begin{tabular}{|l|l|l|l|l|l|l|l|}
\hline & Health centres & 0 & 0.0 & 14 & 70.0 & 6 & 30.0 \\
\hline Haematinics & County General hospital & 0 & 0.0 & 0 & 0.0 & 1 & 100.0 \\
\hline & County hospital & 0 & 0.0 & 2 & 50.0 & 2 & 50.0 \\
\hline & Sub-County Hospital & 0 & 0.0 & 3 & 42.9 & 4 & 57.1 \\
\hline & Health centres & 3 & 15.0 & 11 & 55.0 & 6 & 30.0 \\
\hline IV Fluids & County General hospital & 0 & 0.0 & 0 & 0.0 & 1 & 100.0 \\
\hline & County hospital & 0 & 0.0 & 1 & 25.0 & 3 & 75.0 \\
\hline & Sub-County Hospital & 3 & 42.9 & 4 & 57.1 & 3 & 42.9 \\
\hline & Health centres & 5 & 25.0 & 12 & 60.0 & 3 & 15.0 \\
\hline
\end{tabular}

From the results in Table 8 the County General hospital had adequate key drugs that can last for more than one week needed to handle obstetric cases $(100 \%)$. County hospitals had antibiotics that were adequate (75\%). Sub county hospitals and health centres had antibiotics but not adequate $(60 \%)$. Anticonvulsants was available but not adequate in the sub county and health centres $(86 \%$ and $60 \%)$ respectively. Hydralazine was available but not adequate in sub-county and health centres $(71.4 \%$ and $60 \%)$.

\section{Infrastructure:-}

Good infrastructure enhances better service delivery to the patients.These include presence of enough beds, working lights, labour rooms, blood banks, operating theatres and availability of transport and communication. From the focus group discussions, it came out clearly that most of the facilities did not have enough beds to handle the increased case loads of obstetric clients. Most of the facilities had a well functioning transport system though not adequate. All the facilities had mobile phones as a means of communication. Table 9 below is a summary of the presence of labour rooms, blood banks and operating theatres in the facilities in Kakamega County.

Table 9:- Presence of labour rooms, operating theatres and blood banks.

\begin{tabular}{|c|c|c|c|c|c|c|c|}
\hline \multirow{2}{*}{$\begin{array}{l} \\
\text { Infrastructure }\end{array}$} & \multirow[b]{2}{*}{ Facility } & \multicolumn{2}{|c|}{ Not available } & \multicolumn{2}{|c|}{$\begin{array}{l}\text { Available but not } \\
\text { adequate }\end{array}$} & \multicolumn{2}{|c|}{$\begin{array}{l}\text { Available } \\
\text { adequate }\end{array}$} \\
\hline & & $\mathrm{N}$ & $\%$ & $\mathrm{~N}$ & $\%$ & $\mathrm{~N}$ & $\%$ \\
\hline \multirow[t]{4}{*}{ Labour room } & County General hospital & 0 & 0.0 & 1 & 100.0 & 0 & 0.0 \\
\hline & County hospital & 0 & 0.0 & 3 & 75.0 & 1 & 25.0 \\
\hline & Sub-County Hospital & 0 & 0.0 & 5 & 71.4 & 2 & 28.6 \\
\hline & Health centres & 0 & 0.0 & 15 & 75.5 & 5 & 24.5 \\
\hline \multirow[t]{4}{*}{ Blood bank } & County General hospital & 0 & 0.0 & 0 & 0.0 & 1 & 100 \\
\hline & County hospital & 0 & 0.0 & 2 & 50.0 & 2 & 50.0 \\
\hline & Sub-County Hospital & 7 & 100.0 & 0 & 0.0 & 0 & 0.0 \\
\hline & Health centres & 20 & 100.0 & 0 & 0.0 & 0 & 0.0 \\
\hline \multirow[t]{4}{*}{ Operating theatre } & County General hospital & 0 & 0.0 & 0 & 0.0 & 1 & 100. \\
\hline & County hospital & 0 & 0.0 & 3 & 75.0 & 1 & 25. \\
\hline & Sub-County Hospital & 4 & 57.1 & 3 & 42.9 & 0 & 0.0 \\
\hline & Health centres & 20 & 100.0 & 0 & 0.0 & 0 & 0.0 \\
\hline
\end{tabular}

From the results above all the facilities had labour rooms but not adequate; county general hospital(100\%),county hospitals $(75 \%)$,sub county hospitals $(71.4 \%)$ and health centres(75.5\%).County general hospital and county hospitals had blood bank and operating theatres while sub county and health centres did not have.

\section{Maternal and perinatal mortality rate before and after the training:-}

From the records, it was found out that maternal and perinatal mortality rate reduced after the training .In the year 2010, maternal mortality rate(MMR) in county general hospital was 627/100,000 live births , in the county hospitals MMR was 333/100,000 live births .In the sub county hospitals MMR was 458/100,0000 live births, while in the health centres MMR was 80/100,000 live births.After the training, in the year 2015 MMR in county general hospital reduced to 285/100,000 live births. In the county hospitals MMR reduced to 48/100,000 live births .In the sub county hospitals MMR reduced to 41/100,000 live births and in health centres there were no maternal deaths.

Perinatal mortality rate (PMR) before training in the year 2010 was $74 / 1000$ births in county general hospital. In county hospitals PMR was 34/1000 births, in sub county hospitals PMR was 20 and in health centres was 24/1000 
births. After the training in the year 2015, PMR reduced to 45/1000 births in county general hospital. In county hospitals, PMR reduced to 11/1000 births and sub county and health centres PMR reduced to 4/1000 births. Facility in charges reported on the reduction of maternal and perinatal mortality after the training during the interview.

Table 10:- Maternal and perinatal mortality rate before and after the training

\begin{tabular}{|c|c|c|c|c|c|c|c|}
\hline & & \multicolumn{3}{|c|}{ Before The Training } & \multicolumn{3}{|c|}{ After The Training } \\
\hline & Facility & 2010 & 2011 & 2012 & 2013 & 2014 & 2015 \\
\hline $\begin{array}{l}\text { Total live } \\
\text { births }\end{array}$ & $\begin{array}{l}\text { County G. Hospital } \\
\text { County Hospitals } \\
\text { Sub-county hospital } \\
\text { Health - centres }\end{array}$ & $\begin{array}{l}4308 \\
3000 \\
2400 \\
2480\end{array}$ & $\begin{array}{l}5745 \\
3850 \\
2502 \\
2500\end{array}$ & $\begin{array}{l}4659 \\
4025 \\
2680 \\
255\end{array}$ & $\begin{array}{l}4986 \\
4366 \\
2881 \\
4998\end{array}$ & $\begin{array}{l}6679 \\
7176 \\
4176 \\
5043 \\
\end{array}$ & $\begin{array}{l}6308 \\
8212 \\
4855 \\
5162\end{array}$ \\
\hline $\begin{array}{l}\text { Maternal } \\
\text { deaths }\end{array}$ & $\begin{array}{l}\text { County G. Hospital } \\
\text { County Hospitals } \\
\text { Sub-county hospital } \\
\text { Health -centres }\end{array}$ & $\begin{array}{l}27 \\
10 \\
11 \\
2 \\
\end{array}$ & $\begin{array}{l}18 \\
8 \\
9 \\
0 \\
\end{array}$ & $\begin{array}{l}20 \\
7 \\
8 \\
2 \\
\end{array}$ & $\begin{array}{l}23 \\
8 \\
3 \\
0\end{array}$ & $\begin{array}{l}14 \\
6 \\
1 \\
0\end{array}$ & $\begin{array}{l}18 \\
4 \\
2 \\
0\end{array}$ \\
\hline $\begin{array}{l}\text { Maternal } \\
\text { mortality } \\
\text { rate. } \\
\text { Per } 100,000 \\
\text { live births }\end{array}$ & $\begin{array}{l}\text { County G. Hospital } \\
\text { County Hospitals } \\
\text { Sub-county hospital } \\
\text { Health -centres }\end{array}$ & $\begin{array}{l}627 \\
333 \\
458 \\
80\end{array}$ & $\begin{array}{l}313 \\
207 \\
359 \\
0\end{array}$ & $\begin{array}{l}429 \\
174 \\
298 \\
78\end{array}$ & $\begin{array}{l}461 \\
183 \\
104 \\
0\end{array}$ & $\begin{array}{l}210 \\
84 \\
24 \\
0\end{array}$ & $\begin{array}{l}285 \\
48 \\
41 \\
0\end{array}$ \\
\hline $\begin{array}{l}\text { Perinatal } \\
\text { death }\end{array}$ & $\begin{array}{l}\text { County G. Hospital } \\
\text { County Hospitals } \\
\text { Sub-county hospital } \\
\text { Health -centres }\end{array}$ & $\begin{array}{l}320 \\
102 \\
48 \\
59 \\
\end{array}$ & $\begin{array}{l}315 \\
124 \\
40 \\
40 \\
\end{array}$ & $\begin{array}{l}215 \\
101 \\
56 \\
38 \\
\end{array}$ & $\begin{array}{l}220 \\
92 \\
31 \\
32 \\
\end{array}$ & $\begin{array}{l}355 \\
93 \\
31 \\
32 \\
\end{array}$ & $\begin{array}{l}286 \\
90 \\
20 \\
22 \\
\end{array}$ \\
\hline $\begin{array}{l}\text { Perinatal } \\
\text { mortality } \\
\text { rate per } 1000 \\
\text { births }\end{array}$ & $\begin{array}{l}\text { County G. Hospital } \\
\text { County Hospitals } \\
\text { Sub-county hospital } \\
\text { Health -centres }\end{array}$ & $\begin{array}{l}74 \\
34 \\
20 \\
24\end{array}$ & $\begin{array}{l}55 \\
50 \\
16 \\
16\end{array}$ & $\begin{array}{l}46 \\
38 \\
21 \\
15\end{array}$ & $\begin{array}{l}44 \\
32 \\
16 \\
7\end{array}$ & $\begin{array}{l}53 \\
22 \\
7 \\
6\end{array}$ & $\begin{array}{l}45 \\
11 \\
4 \\
4\end{array}$ \\
\hline
\end{tabular}

Relationship between knowledge and skills of staff in EmONC maternal and perinatal mortality rates:-

The association between knowledge and skills of healthcare providers in EmONC and reduction in maternal and perinatal mortality rates is not direct as it is influenced by other factors. Since the training was started in the year 2010, there were a number of strategies that were put in place to reduce maternal and perinatal mortality rate. These included free maternity services that was started in the year 2013, free ambulance services that was started in the year 2014 and the Oparanya care that was started in the year 2014. The Oparanya care was started by the governor to encourage pregnant women to seek ANC services and improve skilled deliveries through giving mothers who complete four ANC visits and deliver in health facility incentives. EmONC training was also among the strategies to reduce MMR and PMR. From the results of focus group discussions, interview with in charges and the quantitative analysis of results it showed that the training reduced the MMR and PMR in the facilities in Kakamega County.

\section{Discussions:-}

The respondents showed strong support for in-service training to handle obstetric emergencies. Respondents felt that in-service EmONC training would improve facilities' ability to appropriately manage obstetric emergencies. A comment was made by a nurse who opined that:

"to provide good service, we needed to improve our knowledge. We might have been creating problems for our clients because we didn't have updated information or adequate knowledge." (Male, Health Centre, Bsc Nurse)

Though the duration of EmONC training is short compared to pre service training, it is very intensive with much time allocated to skills. In addition to that, the breakout sessions in EmONC training makes the learning more interesting and with much concentration leading to adequate knowledge and skills acquired compared to other in service trainings.

There was an improvement in the knowledge on EmONC service delivery among the staff. A chi square test showed $p<0.05$. This showed that there was significant association between the performance before and after the training, hence a positive improvement from the previous delivery of EmONC services. The training improved the knowledge of staff providing EmONC services. Staffs are able to confidently provide emergency services in 
maternity. This reduced maternal and perinatal mortalities in the facilities. Staff have now have the skills needed in handling obstetrics and neonatal emergencies and also skills in managing normal labour and normal newborn.

EmONC training can, when adapted to the developing world context, improve the quality of staffs' skills and reduce maternal mortality. In one of the focused group discussion, one of the respondents said this;

"The training was of great importance in our maternity because staffs have no adequate knowledge and skills regarding EmONC hence this improved the quality of care of clients in maternity leading to a reduced maternal and neonatal mortality. Staffs morale of work also improved because of good knowledge and skill."(Female nurse in one of the facilities).

This showed that the training had a positive effect to the respondents and improved their knowledge in the provision of EmONC services. Staff have now all the skills needed in handling obstetrics and neonatal emergencies. The high number of referrals to the County General hospital makes the changes in maternal and perinatal mortalities realized in the four county hospitals, sub county hospitals and health centres.

This study concurs with that of Ameh (2012) where he affirms that healthcare providers who underwent EmONC training in Somalia reported improved confidence in providing emergency obstetric care. The training also impacted positively on the availability and quality of EmONC and resulted in up skilling of midwives (Ameh, 2012). Historical analysis of maternal mortality trends in western Europe suggest that having a skilled attendant at delivery within the context of a supporting environment (respect from professionals and the community, training and supervision) before the availability of EmOC lowered maternal deaths to an extent (Ameh, 2012).Sullivan et al, (2008) also suggests that the simulated practice ensures the learning and mastery of all EmONC skills and minimizes risk during practice on patients.

From the results $\mathrm{p}<0.05$, respondents' skills on neonatal care greatly improved. This was also highlighted in a focus group discussion in one of the facilities when a participant said the following;

"Neonatal resuscitation was a big challenge to us, we had to depend on anaesthetist to assist in resuscitating a newborn but now after the training we are able to perform the procedure comfortably and we have saved lives of many neonates" (Nurse in a sub county hospital).

This study also concurs with a study carried out in the UK which found out that after EmONC training there was a reduction in diagnosis delivery interval from 25 to 14.5 minutes and there was an increase in the proportion of caeserian sections where recommended actions had been performed (from 34.78\% to 82.5\%) (Siassako, 2009).This shows that the staffs' knowledge and skills improved.

\section{The factors influencing implementation of EmONC services:-}

EmONC training of staff was one of the appropriate strategies embraced by the county to reduce the high maternal and perinatal mortality. Despite the fact that staffs had now the skills and knowledge in EmONC, there were factors that affected their performance as depicted during the focus group discussions and analysis of the results.

The health centres and sub county hospitals offer basic obstetric emergency and neonatal services and so if an obstetric client develops a complication that needs caeserian section or blood transfusion then will be referred to county hospital which offers comprehensive emergency obstetric and neonatal care services. Giving birth is a natural process, but transition from a routine to an emergency situation can occur rapidly and unexpectedly (Nielsen et al., 2007). Distance of most of the facilities from the referral facility is over 20 kilometres hence making it difficult for clients with complications to reach at the referral facility on time. This shows that even with proper training of staff the distance hampers the provision of EmONC services. At the time of an obstetric emergency, every moment of delay in seeking and receiving skilled care increases the risk of maternal deaths/disability and stillbirths.

According to World Health Organization (2011) staffing pattern, in labour ward during normal delivery there must be a ratio of midwives to client 2:1. In maternity theatre during caeserian section there must be a ratio of $7: 1$ while in antenatal and postnatal there must be a ratio of 1:6.From the focus group discussion, the participants came up with a challenge of inadequate staff in maternity departments. During night duties and weekends there are nurse midwives only on duty. In county hospitals there only two nurses on duty during night duty and weekends while in sub county and health centres there is only one nurse on duty during weekends and night duty. Doctors and consultants operate 
on call .This interferes with delivery of EmONC services. This concurs with a study carried out in Afghanistan to determine the availability and distribution of human resources to provide CEmONC identified gaps between the actual number of skilled providers and the recommended staffing paradigm which is a common barrier to maternal care (Manizha et al,2015).

EmONC emphasizes on quality services offered to clients which depends on availability of good infrastructure. It was identified during the discussion that the ambulances are available in the facilities but are not adequate to handle the increased referrals leading to delay in referral of clients with complications. All the facilities have labour rooms but the space is not adequate enough to accommodate the increasing number of obstetric clients .One participant commended the following:.

"Before we refer a patient we have to call the referral facility first to inform them but sometimes we are told to wait or refer to another facility because of inadequate beds and space in the referral facility."

The study concurs with that of Austin (2015) who affirms that lack of space and enough beds interfered with delivery of EmONC in Ethiopia .Patients were accepted in a receiving facility if there was a bed but if not they were referred to other facilities.

Health centres and sub county hospitals do not have blood banks and operating theatres. This leads to delay in delivery of emergency caeserian section or blood transfusion for patients who need the service because they have to refer .This agrees with the study carried out in Ethiopia to identify barriers to providing quality EmONC identified lack of transportation and communication infrastructure and overcrowding at the referral hospitals as challenges for smooth functioning of the referral network (Austin, 2015).

The concept of EmONC is based on assumption that maternal complications occur in around $15 \%$ of deliveries. When such complications occur, maternal mortality could be prevented in a setting where skilled health attendants, drugs and medical supplies needed are available (Mkoka et al., 2014). The key drugs in maternity include antibiotics for the treatment of postpartum infections, anticonvulsants for management of preeclampsia and eclampsia, hydralazine for the treatment of high blood pressure and intravenous fluids for the management of post partum haemorrhage. The above complications are the major causes of maternal mortality (Ameh, 2015).

County general hospital has all the key drugs that can last for more than one week. Sub county hospitals do not have adequate anticonvulsants (86\%).Same to health centres (60\%).Sub county hospitals and health centres do not have adequate hydralazine and intravenous fluids $(71.4 \%$ and $60 \%)$ respectively .This hampered the timely delivery of EmONC services in health centres and sub county hospitals because clients who developed complications were to be referred to other facilities.

Team work improved after the training as this was evident during focus group discussions in various health facilities .One participant said the following:

"Before training, we left obstetric emergencies for doctors assuming that they were the ones to handle emergencies but after training which stressed on team work during an emergency every staff has a role to play". (Midwife in county hospital).

The training involved all the front line health care workers and equipped them with knowledge and skills and they were able to handle emergencies from the peripheral facilities up to the referral facilities. Before training doctors attended to emergencies more than other cadres.After training the number of other cadres who attend to emergencies increased.From the interview with maternity in charges it came out that nurses who are many than other cadres and they stay with clients most of the time they can handle emergencies and so do not depend on doctors to handle emergencies unless very complicated ones that needed surgery. This contributed to reduction of maternal and perinatal mortality rate in Kakamega County .This study concurs with that of birch(2007) who affirms that multi-professional teams that are taught to manage obstetric emergencies using simulation are more likely to demonstrate sustained improvements in their confidence, knowledge and clinical management of emergency situations. Introduction of multidisciplinary teamwork training with integrated acute obstetric training interventions in a simulation setting is potentially effective in the prevention of errors thus improving patient safety in acute 
obstetric emergencies (Req uejo, 2010). This confirms that EmONC training in Kakamega county involved multiprofessionals and are able to manage obstetric emergencies same to other areas in the world.

\section{Maternal and perinatal mortality before and after the training:-}

The number of maternal and perinatal mortality rate reduced compared to before training In the year 2010, maternal mortality (MMR) rate was 627/100,000 live births. The county hospitals had MMR of 333/100,000 live births .Sub county hospitals had MMR of 458/100,000 live births. Health centres had MMR of 4/100,000 live births .After the training in the years 2013, 2014 and 2015, MMR reduced .For example in the year 2015, County general hospital had MMR of 285/100,000 live births. County hospitals had MMR of 48/100,000 live births .Sub county hospitals had MMR of 41/100,000 live births. Health centres did not have maternal deaths .Perinatal mortality rate (PMR) in year 2010 in county general hospital was 74/1000 births county hospital was34/1000 births in sub county hospitals was20/1000 births and health centres was $24 / 1000$ births. In the year 2015 after the training county general hospital had PMR of 45/1000 births, sub county hospitals had PMR of 4/1000 births and health centres had PMR of 4/1000 births. This showed that the training led to the reduction of maternal and perinatal mortalities in Kakamega County. County general hospital records high maternal and perinatal mortality because it is the county referral hospital. It also records the highest number of deliveries but the mortalities reduced after the training.

This concurs with a study carried out in Bangladesh a randomized controlled trial which showed that midwives trained in EmONC in BEmONC facilities were able to manage emergencies well and those emergencies beyond their capacities were actively referred to CEmONC facilities which reduced maternal mortality by nearly $50 \%$ (Ameh, 2012). Combining skilled attendance at delivery with EmONC in Western Europe and the US rapidly and dramatically transformed maternal mortality such that it disappeared as a public health concern within a few years (Apaxton et al, 2005). A study on newborn care training and development revealed that training birth attendants in essential newborn care with a component of obstetric care and neonatal care training was associated reduction in still births thus improving outcomes in the developing world (Waldamer, 2014). An evaluation study done in Moi Referral and Teaching hospital to evaluate the impact of EmONC training programme revealed that the introduction of EmONC training improved maternal outcomes (Spitzer et al, 2014).

\section{Conclusion:-}

EmONC training improved the staffs' knowledge and skills. Staffs are able to confidently provide emergency obstetric services in maternity. In addition the training enhanced teamwork among all the staffs working in maternity. This contributed to reduction in maternal and perinatal mortalities in the health facilities. However, long distances to the referral facility, inadequate means of transportation, inadequate staff and poor infrastructure were found to be major challenges affecting timely delivery of EmONC services. Maternal and perinatal deaths could be averted more if all women are delivered in a facility that has the capacity to provide EmONC and/or life-saving interventions in the event of obstetric complications. The County government therefore should address the challenges interfering with implementation of EmONC services within the health facilities.

\section{References:-}

1. Turab A, Arif S, Muhammad A. H, ,Ahmed ,Iand Rashid,A. Improved Accessibility of EmONC services for Maternal and Newborn Health.BMC pregnancy and child birth, 2013,11-15..

2. Apaxton, D, main,L, .Freedman,S, .Lobis,A, Verting Maternal Death and Disability Mailman school of Public Health,Columbia University,60 Haven Avenue,10032 Newyork USA,2005 181-193.

3. Austin A, Gulema H, Belzan N. et al. Barriers to Providing Quality Emergency Obstetrics in Addis Ababa Ethiopia. BMC Pregnancy and Child Birth, 2015

4. Birch L, Jones N, Doyle PM, Green P, McLaughlin A, Champney C, et al. Obstetric skills drills:evaluation of teaching methods. Nurse Educ Today 2007; 27:915-22.

5. Campbell O M, Graham WJ, Lancet Maternal Survival Series steering group: Strategies for reducing maternal mortality: getting with what works. Lancet 2006, 368(9543):1284-99

6. Ameh C, Adegoke A, Hofman J and Ismail F I, (2012). Evaluation of in service training in life saving skills; 3:019.

7. Ameh C.,Emergency obstetrics and neonatal care training Liverpool School of Tropical Medicine 2015.

8. Crofts JF, Bartlett C, Ellis D, Hunt LP, Fox R, Draycott TJ. Training for shoulder dystocia: a trial of simulation using low-fidelity and high-fidelity mannequins. Obstet Gynecology, 2006; 108:1477-85. 
9. Crofts JF, Bartlett C, Ellis D, Winter C, Donald F, Hunt LP, et al. Patient-actor perception of care: a comparison of obstetric emergency training using manikins and patient-actors.Quall Health Care ,2008; 17:20-4.

10. Mkoka DA, Goicolea, I, ,Kiwara A et al. Availability of Drugs and Medical Supplies for emergency obstetric care, 2014:

11.

12. Lewis G, editor. The Confidential Enquiry into Maternal and Child Health (CEMACH).Saving Mothers' Lives: Reviewing Maternal Deaths to Make Motherhood safer,2003-2005.

13. Nielsen PE., Goldman MB, Mann S, Shapiro DE, Marcus RG, Pratt SD, et al. Effects of teamwork training on adverse outcomes and process of care in labor and delivery: a randomized controlled trial. Obstet Gynaecology 2007; 109:48-55.

14. Requejo Bruce Status of maternal and child health in UK .Obstet and Gynaecology 2010

15. Siassakos, Hasafa, Sibanda, Fox: Retrospective Cohort study of diagnosis-delivery interval with umbilical cord prolapsed: the effect of team training may 2009 BJOG An International Journal of obstetric and gynaecology.

16. Starrs, A. M. (2006). "Safe motherhood initiative: 20 years and counting." Lancet 368 (9542): 1130-2.

17. Waldermar A. Cario, shivaprasad, Imtiaz Jehan Elwyn Chomba; Newborn-care Training and Perinatal Mortality in Developing countries, 2010: 362: 614-623.

18. WHO (2009).Guidelines for Management of PPH and retained placenta.

19. WHO Trend in maternal mortality 1990 to 2013. Estimates by the WHO, 2014

20. WHO, (2005). The Millennium Development Goals Report.

21. World Health Organisation Recommendation for the prevention and treatment of post partum haemorrhage. Geneva. WHO: 2012 PMID: 23586122.

22. World Health Organisation 2011 (World Health statistics. Geneva) 